J Child Adolesc Psychopharmacol Vol. 13(1):29-40 (2003)

ISSN: (print 1044-5463) (online 1557-8992)

doi: $10.1089 / 104454603321666171$

This is a peer reviewed pre-print version of the following article: Methylphenidate Treatment in Children with Borderline IQ and Mental Retardation: Analysis of Three Aggregated Studies, which has been published in final form at:

http://www.liebertpub.com

http://www.liebertpub.com/cap

http://www.liebertonline.com/doi/abs/10.1089/104454603321666171

(C) 2003 Mary Ann Liebert, Inc. Publishers

\title{
Methylphenidate Treatment in Children with Borderline IQ and Mental Retardation: Analysis of Three Aggregated Studies
}

\author{
Michael G. Aman, Ph.D., Department of Psychiatry, School of Medicine, University \\ of Auckland, Auckland, New Zealand, The Nisonger Center for Mental Retardation, \\ Ohio State University, 1581 Dodd Drive, Columbus, Ohio, Brett Buican, Ph.D., The \\ Nisonger Center for Mental Retardation, Ohio State University, 1581 Dodd Drive, \\ Columbus, Ohio, and L. Eugene Arnold, M.D., M.Ed. Department of Psychiatry, \\ Ohio State University, Columbus, Ohio.
}

Abstract

To determine response of low-IQ children with attention deficit hyperactivity disorder (ADHD) symptoms to methylphenidate (MPH).

Methods:

An aggregated analysis was conducted in 90 children with low IQ who received the same dose regimen of MPH in three independent, placebo-controlled studies. Active drug and placebo were given from 2 to 4 weeks each. Outcome measures included teacher and parent ratings on standardized behavior scales (mean $n=84)$, performance on computer-controlled cognitive-motor tests $(n=62)$, and measures of cardiovascular response $(n=85)$.

Results:

Both teachers and parents rated the children consistently as being improved on subscales assessing attention, overactivity, and conduct problems. Some $44 \%$ of the subjects showed at least a $30 \%$ reduction compared with placebo on teacher ratings. MPH improved accuracy on several cognitive tests, response speed was increased on some, and seat activity declined for one of three tests; heart rate was mildly increased (3.9 beats/minute) with MPH. Analyses of IQ and mental age as moderator variables suggested that lower functional level (especially lower IQ) may be associated with a less favorable response to MPH.

Conclusions:

Children with low IQ and ADHD clearly respond to MPH, but their rate of beneficial response appears to be well under that of normal-IQ children and more varied. Different attentional mechanisms may moderate response to psychostimulants.

\section{Introduction}

It has long been known that the use of psychostimulants (e.g., methylphenidate [MPH], dextroamphetamine, and d-l-amphetamine) is the treatment of choice in normally developing children with attention deficit hyperactivity disorder (ADHD) (Barkley et al. 1999; Wilens and Spencer 2000). However, the earliest studies of psychostimulants in patients with mental retardation were often negative. Gadow (1985), who reviewed this literature, noted that presence 
of institutional environments, the choice of target symptoms often unrelated to ADHD, and frequent selection of subjects across the age span made interpretation of these studies very problematic.

Since 1980, several good studies (all placebo controlled with crossover designs) have been conducted with children having both a developmental disability and ADHD. Hagerman et al. (1988) assessed dextroamphetamine $(0.2 \mathrm{mg} / \mathrm{kg})$ and MPH $(0.3 \mathrm{mg} / \mathrm{kg})$ in children with fragile X syndrome and attention deficit disorder (mean IQ = 58; range 29-77). Teacher ratings (but not parent ratings) showed significant benefit with MPH; 10 of the 15 subjects $(67 \%)$ were considered responders to either MPH or dextroamphetamine. Handen et al. (1990) assessed MPH in doses of 0.3 and $0.6 \mathrm{mg} / \mathrm{kg}$ in 12 children (mean IQ $=65$; range 50-74). Teacher ratings on both the Conners' Abbreviated Symptom Questionnaire (CASQ, sometimes called the Hyperkinesis Index) and the Conners' Teacher Rating Scale (CTRS) showed reductions in attention problems, over-activity, and conduct problems at both doses. Handen et al. (1992) again compared placebo and $0.3 \mathrm{mg} / \mathrm{kg}$ and $0.6 \mathrm{mg} / \mathrm{kg} \mathrm{MPH}$ in 14 children with ADHD (mean IQ =66; range 48-74). Once again, ratings on the CASQ and CTRS consistently showed significant improvement with both doses of MPH. Handen et al. (1996) compared placebo and 0.3 and $0.6 \mathrm{mg} / \mathrm{kg} \mathrm{MPH}$ in 44 children (mean IQ = 64.3; range 44-77); this report included children from Handen et al. (1992). Both active doses resulted in significant improvements on the CASQ, CTRS, and the Childhood Attention Problem Scale (Edelbrock 1978) as assessed by teachers. Pearson et al. (2003) recently reported a study of 24 children, with a mean IQ of 56.5, who received placebo and doses of 0.15 , 0.30, and $0.60 \mathrm{mg} / \mathrm{kg} \mathrm{MPH}$. As assessed by CTRS, CASQ, and the Attention Deficit Disorder with Hyperactivity Comprehensive Teacher's Rating Scale (Ullmann et al. 1997), the high dose (0.6 $\mathrm{mg} / \mathrm{kg}$ ) was consistently superior to placebo ( $82 \%$ of subscales), and the middle dose $(0.3 \mathrm{mg} / \mathrm{kg})$ was inconsistently superior (27\% of the subscales). Only 1 of 19 parent-rated subscales was sensitive to medication, and this was confined to the high dose.

Thus, most of the studies in the mental retardation field have used relatively low MPH doses in the range of 0.15 to $0.60 \mathrm{mg} / \mathrm{kg}$, and most have been successful in showing beneficial changes in behavioral indices of attention and activity. Arnold et al. (1998) reviewed these and other studies in children with developmental disabilities, and they noted that the psychostimulants are clearly an effective treatment for co-occurring ADHD symptoms. Aman (1996) also reviewed this literature, concurred about overall drug response, and observed that clinical response was more heterogeneous in children with mental retardation (with a response rate around 55\%) than in normal-IQ children, possibly lower still in children with autistic disorder (see also Aman and Langworthy 2000). However, to forecast an issue that is discussed in more detail later in this article, there are reasons to believe that children with mental retardation and ADHD may be more prone to adverse effects than typically developing children with ADHD.

Our group has completed three independent studies (with about 30 subjects each) of MPH in children with low IQs (Aman et al. 1991, 1993, 1997). Certain procedures, including choice of drug, dosing regimen, and assessments, were held constant across these studies. The prevalence of mental retardation is about $1 \%$, and the co-occurrence of fullblown cross-situational ADHD symptoms in addition to mental retardation is uncommon (perhaps 10-12\%) (Benson and Aman 1999). Hence, the 90 participants having such low IQ and hyperactivity provide an opportunity to study the largest such sample ever assembled for research of these targets. In this report, we present an aggregate analysis of common variables collected in the three studies.

\section{Methods}

\section{Subjects}


Study 1.

The participants were 32 New Zealand children and adolescents attending special schools, special classes, or special resource classes for children with mental retardation. Age ranged from 4 to 17 years $($ mean $=10.1, \mathrm{SD}=3.1$ years). IQs ranged from unmeasurable to 90 (mean $=52.8, \mathrm{SD}$ $=20.3)$. There were 27 boys $(84.4 \%)$ and 5 girls $(15.6 \%)$. Ethnicity was as follows: Caucasian $(n=$ $22,68.8 \%)$, New Zealand Maori $(n=6,18.8 \%)$, and Pacific Islander $(n=4,12.5 \%)$.

Entry criteria required each child to meet Diagnostic and Statistical Manual of Mental Disorders, third edition (DSM-III; American Psychiatric Association 1980) criteria for attention deficit disorder (ADD) $(n=29)$ or conduct disorder (CD) $(n=1)$ or both ADD and CD $(n=2)$. Rating scales completed by parents and teachers and a structured interview using the Diagnostic Interview Schedule for Parents (DISC-P) (Shaffer et al. 1989, unpublished manuscript) along with a clinical interview supported the diagnosis. Twenty-four of the subjects met DSM-III criteria for attention deficit disorder with hyperactivity (ADD-H). Four were diagnosed as having attention deficit disorder without hyperactivity, and one had attention deficit disorder, residual type. Three participants had a conduct disorder, and one child had pervasive developmental disorder not otherwise specified (PDD-NOS) in addition to ADD-H. Other than conduct disorder, autistic disorder, and PDD-NOS, the participants were not screened for additional DSM disorders.

Study 2.

The subjects were 28 American children, aged 5 to 13 years (mean age $=8.8, \mathrm{SD}=2.6$ years). There were 20 boys $(66.7 \%)$ and 8 girls $(33.3 \%)$. The children's IQs ranged from untestable ( 2 children) to 78, with a mean of 61.0. There were three African American and 25 Caucasian children in this group. Inclusionary criteria were the following: (a) IQ $\leq 80$, (b) presence of severe inattention or hyperactivity as assessed on the CTRS (i.e., exceeding 90th percentile on the Inattention or Hyperactivity subscales relative to norms), (c) presence of severe inattention or motor excess as rated by parents on the Revised Behavior Problem Checklist (RBPC; Quay and Peterson 1987) (i.e., exceeding the 90th percentile on these subscales), (d) professional diagnosis of ADHD based on DSM-III-R criteria (American Psychiatric Association 1987), and (e) aged between 5 and 13 years. Exclusion criteria included the following: (a) motor handicap, (b) autism or symptoms of psychosis, (c) epilepsy, and (d) Down syndrome (excluded because Down syndrome was thought to be a possible contraindication for one of the two study drugs, fenfluramine).

Study 3.

The inclusionary and exclusionary criteria were the same as for study 2, with some minor exceptions. First, age extended from 5 to 14 years. Second, the upper limit for IQ was 84 rather than 80 . Otherwise all criteria were identical. In all, 35 children participated. Five of these were dropped because of noncompliance with the protocol. There were 22 boys and 8 girls. Mean age was 7.7 years $(\mathrm{SD}=2.5$ years). There were 5 African American subjects $(16.7 \%), 1$ Hispanic (3.3\%), 1 Asian (3.3\%), 21 Caucasian (70.0\%), and $2(6.7 \%)$ with mixed ethnicity (African American and Caucasian). IQs extended from the basal score (36) to 84, with a mean of 61.8 (SD $=13.63$ ). We did not attempt to do formal psychiatric diagnoses for comorbidity, but the participants' parents did complete the Stony Brook Checklist-3R (Gadow and Sprafkin 1987, unpublished manuscript), a screening instrument based on DSM-III-R criteria. The numbers screened for each comorbid disorder were as follows: conduct disorder $(n=7)$, oppositional defiant disorder $(n=3)$, overanxious disorder $(n=2)$, and separation anxiety disorder $(n=6)$. Two 
of the children had PDD-NOS.

Combined sample.

When all three samples were combined, we had a pooled sample of 90 children, with an age range extending from 4 to 17 years (mean $=9.0, \mathrm{SD}=2.9$ years). IQ ranged from untestable to 90 , with a mean of $58.5(\mathrm{SD}=16.1)$. Mental age extended from 1.9 to 9.9 years $($ mean $=4.9, \mathrm{SD}=$ 1.87 years). There were 69 boys (76.7\%) and 21 girls $(23.3 \%)$. Ethnicity was as follows: African American $(n=8,8.9 \%)$, Asian $(n=1,1.1 \%)$, Caucasian $(n=68,75.6 \%)$, Hispanic $(n=1,1.1 \%)$, Maori $(n=6,6.7 \%)$, Pacific Islander $(n=4,4.4 \%)$, and mixed (African American and Caucasian) $(n=2,2.2 \%)$. Almost all of the children were in special educational placements, usually in classrooms designated for children with mental retardation. Furthermore, although nine of these children currently tested above the mentally retarded range (i.e., above 75), most of these had at some previous time been found to have mental retardation as assessed on IQ and adaptive behavior scales (e.g., one child in Aman et al. 1993; five children in Aman et al. 1997). After complete description of the study to the parents, written informed consent was obtained. A multitude of events (e.g., the winter blizzards of 1994 and failure of teachers to mail forms) and some outliers (see the Data Analysis section) caused some data loss. In addition, only about $70 \%$ of subjects could perform the cognitive tests. As a result, the mean sample size for the clinical (rating scale) measures was 84 , for cardiovascular measures 85 , and the mean sample size for the cognitive tests was 62.

\section{Design}

All three studies employed crossover designs, and all three included a double-blind comparison of placebo, MPH $(0.40 \mathrm{mg} / \mathrm{kg})$ given in the morning only, and another drug. This standardized dose of MPH was selected because previous studies in typically developing children suggested that the dose fell midway between an optimal dose for performance on a short-term memory task (i.e., $0.3 \mathrm{mg} / \mathrm{kg}$ ) and behavior (i.e., around $0.70 \mathrm{mg} / \mathrm{kg}$ ) (Sprague and Sleator 1973, 1977). Not all attempts to replicate these dose response curves have been successful (see Richters et al. 1995).

Study 1 was a comparison of placebo, MPH, and thioridazine (Mellaril, USA) given in divided daily doses of $1.75 \mathrm{mg} / \mathrm{kg}$. Each drug condition was given for 3 weeks. Study 2 was a comparison of placebo, MPH, and fenfluramine (Pondimin, USA) given in divided daily doses of $1.50 \mathrm{mg} / \mathrm{kg} /$ day. All three conditions were given for 4 weeks each. Study 3 was a comparison of placebo, MPH, and three doses of fenfluramine $(1.0,1.5,2.0 \mathrm{mg} / \mathrm{kg} /$ day) given in divided daily doses. Each medication was given for 2 weeks. Studies 1 and 2 used Latin square designs to balance drug order and time; there were three drug orders for each study. Study 3 used two mirror-image Latin squares, and each drug condition appeared equally often at each possible time point.

Thus, all participants received placebo and the same dose of MPH, given in the same regimens (once daily, administered before going to school). The order of medication (placebo first, MPH second, and vice versa) was balanced, although sometimes comparator medicines were administered between them. Equal numbers of children received placebo first and MPH second and vice versa. There were no interactions in these studies between drug order and drug effect on any of the outcome variables showing a significant drug effect. On the last day of each drug period, all subjects were brought by their parents to the laboratory for standardized assessments, which included parent ratings, heart rate and blood pressure assessment, and evaluation of cognitive performance using computer-controlled equipment. These assessments were usually begun 60 to 
90 minutes after morning medication.

\section{Measures of drug change}

With the exception of the Aberrant Behavior Checklist (ABC; Aman et al. 1985), all variables described below were used in all three studies. The ABC was used only in studies 2 and 3.

\section{Behavioral measures.}

The children were rated by their teachers on the CTRS (Conners 1969) and the ABC (Aman et al. 1985). The 39-item CTRS was developed by factor analysis with typically developing children; it has four subscales: Conduct Problem, Inattention, Tension/Anxiety, and Hyperactivity. Furthermore, we derived a score for the CASQ from the CTRS. The CASQ is a 10-item instrument, comprising items related to ADHD and emotionality, that has often been used in drug research (Aman and Pearson 1999; Goyette et al. 1978). The ABC was developed by factor analysis with children and adults having mental retardation. Its five subscales are designated as: Irritability, Lethargy/Social Withdrawal, Stereotypic Behavior, Hyperactivity/ Noncompliance, and Inappropriate Speech.

Parents rated their children on the Revised Behavior Problem Checklist (RBPC), an 89-item instrument also developed by factor analysis with typically developing children (Quay and Peterson 1987). Its six subscales were designated as follows: Conduct Problem, Socialized Aggression, Attention Problem, Anxiety/Withdrawal, Psychotic Behavior, and Motor Excess. The RBPC has frequently been used in clinical research, especially that involving conduct and aggressive disorders, but it has not been frequently used in drug research (Aman and Pearson 1999). Because we did not regard the Socialized Aggression subscale as relevant for many of our participants, we deleted the items from this subscale. Parents also rated their children on the CASQ and on the $\mathrm{ABC}$ described earlier.

\section{Cardiovascular.}

Each time the children visited the laboratory, their radial heart rate and blood pressure were monitored by a physician with the subject seated following a 5-minute period of rest.

\section{Cognitive performance and activity level.}

Each time the subject visited the laboratory, he or she was assessed on a cognitive battery that was mostly computer controlled. There is a body of psychometric data on all of the performance measures used. Each of the tests has adequate reliability, validity, and drug sensitivity to be a useful measure of treatment outcome (see Aman 1991). The following tests were included.

1. Matching to Sample (MTS) task: The MTS task was developed to assess memory in pigeons (Cumming and Berryman 1965). We adapted it for use in children with low IQ. Our version involved the repeated presentation of three colors: red, yellow, and blue. One color was presented at the center-top of the screen. The subject then pressed the screen to indicate that he or she saw the stimulus. One second later, the colors red, yellow, and blue were displayed at the bottom of the screen. The child's job was to locate the color that matched that previously seen and to press that part of the screen. Each time the child got three consecutive trials in a row correct, the computer added 1.0 second to the delay between the test stimulus and the response stimuli. Each time the subject erred, the computer subtracted 1.0 second, down to a minimum of 1.0-second delay. Four measures 
were derived from this task: accuracy, longest delay achieved, mean delay, and mean response time (time for subject to decide and press the screen).

2. Matching Familiar Figures (MFF) task: The MFF task is said to measure the subject's ability to pause and reflect on a complex problem, but the task clearly also tests the ability to perceive minor differences between stimuli (Aman 1991; Kagan 1965). In our version of the MFF task, a probe stimulus was presented at the center-top of the screen, and four test stimuli were simultaneously presented across the bottom of the screen. All of the figures were drawn to be quite similar, but only one of the four stimuli at the bottom was identical to the one at the top. The child's task was to find the test stimulus that matched the probe and to push the button corresponding to that stimulus. Two variables were collected, namely, accuracy (percent correct) and response time.

3. Continuous Performance Task (CPT): The CPT used in this study employed two pictures, one of a princess and one of a witch (Aman 1991). The child was told to warn the princess by pressing a lever when the witch appeared and to refrain from responding when the princess appeared on the screen. This test of attention span took about 8 minutes to complete. There were 162 trials in all, 40 of which were the target (i.e., witch). The variables included failures to detect the witch (omission errors), incorrect detections when the princess was displayed (commission errors), and mean response time.

4. Seat Movement: The chair on which children sat was equipped with a pivot at its center and a microswitch under each of the sides (Aman 1991). Each tilt of the seat resulted in closure of one of the microswitches, which was automatically recorded by the computer. Only activity occurring during the constant (computer-controlled) portions of the test was recorded. All tests listed here have been described much more fully in Aman (1991).

\section{Data analysis}

Prior to inferential analyses, the data were examined for the presence of outliers and deviations from normality. The data screening occurred in a two-step process. First, extreme values (defined by SPSS [Statistical Package for the Social Sciences, Version 9.0, computer software, Chicago SPSS, 1998] as 3 times the interquartile range - the distance between the first quartile [25th percentile] and third quartile [75th percentile]) were identified for each variable and then excluded. Next, data were checked for degree of skew. When skewed, data were transformed using a square root, logarithmic, or inverse transformation, depending on the degree of skew (criteria: skew $<0.8$, no transformation; skew 0.8-1.5, square root; skew 1.5-3.0, logarithmic; skew $>3.0$, inverse). The type of transformation, if present, is presented after each variable $(\mathrm{S}=$ square root, $\mathrm{L}=$ logarithmic, $\mathrm{I}=$ inverse). All such transformations were performed and outliers removed before any data analyses were conducted.

For the main analysis, we used an analysis of variance (ANOVA) model, and we assessed for the effects of (a) study (1, 2, or 3; between-subjects factor) and (b) drug (placebo vs. MPH; within-subject factor). We also conducted secondary analyses to see if IQ or mental age had significant effects on outcome. For these analyses, we used a three-way ANOVA model and analyzed as a function of (a) either IQ (greater than/less than 50) or mental age (greater than/less than 4.5 years) (between subjects), (b) study, and (c) drug.

\section{Results}

Because of the number of variables assessed, we set alpha at $p=0.01$. Because there are so few reports on stimulant effects in children with mental retardation, we identified changes at the 0.05 level of significance to enable readers to make exploratory comparisons (see Tables 1 and 3 ). 


\section{Behavioral changes}

Results for the teacher and parent ratings are presented in Table 1. In general, subscales assessing attention problems and motor excess showed a significant advantage for MPH over placebo. There were only two minor exceptions (no effect for attention problem on the RBPC and parent CASQ). Although MPH was only given once a day, both teachers and parents were reliable in detecting differences between drug and placebo.

We derived a definition of responder by using teacher ratings on the CASQ to calculate response rate. We did this by calculating the number of children to show improvement in $10 \%$ increments using the following formula: (Placebo $2 \mathrm{MPH}$ )/Placebo. Table 2 shows the rates of clinical response for various criteria (20\% improvement, $30 \%$ improvement, etc.). If we arbitrarily classify children who showed more than $30 \%$ improvement as responders, then 36 of 81 children $(45 \%)$ were responders. Another way to gauge change is to examine effect sizes, which were calculated for significant subscales related to inattention or overactivity. For teachers, the effect sizes were: CTRS Inattention, 0.46; CTRS Hyperactivity, 0.69; CASQ, 0.56; and ABC Hyperactivity, 0.58 (mean $=0.57$ ). For parents, the effect sizes were usually smaller: RBPC Motor Excess, 0.26; ABC Hyperactivity, 0.35; and Global Rating, 0.56 (mean =0.39).

Results from the cognitive tests are presented in Table 3. All significant changes (6 of 13; $46 \%$ ) indicated improvement with MPH. On the MTS task, subjects had greater accuracy and shorter response times with $\mathrm{MPH}$. On the CPT, both errors of omission and errors of commission were greatly reduced (by $40.0 \%$ and $49.6 \%$, respectively); response time was significantly reduced as well. Seat movement was significantly reduced only during the CPT (by 33.6\%).

\section{Cardiovascular changes}

Heart rate was increased with MPH (3.9 beats/minute); the increases in diastolic and systolic blood pressure just failed to reach the 0.01 level of significance ( 2.9 and $2.1 \mathrm{~mm} \mathrm{Hg}$, respectively).

\section{Secondary analyses: Subject variables associated with clinical response}

In an effort to determine if there were useful subject variables that helped to predict clinical outcome, we divided the subjects by mental age $(<4.49$ or $\geq 4.50$ years) and by IQ $(<49$ or $\geq 50)$. These division points were chosen because they were very close to the median 


\begin{tabular}{|c|c|c|c|c|c|}
\hline \multirow[b]{2}{*}{ Variable } & \multicolumn{2}{|c|}{ Placebo } & \multicolumn{2}{|c|}{ Methylphenidate } & \multirow[b]{2}{*}{$\mathrm{F}$} \\
\hline & Mean & $S D$ & Mean & $S D$ & \\
\hline \multicolumn{6}{|l|}{ Teacher } \\
\hline \multicolumn{6}{|l|}{ CTRS } \\
\hline Conduct Problema,b & 1.97 & 0.67 & 1.64 & 0.46 & $3.29^{*}$ \\
\hline Inattention $\mathrm{a}, \mathrm{b}$ & 2.58 & 0.74 & 2.24 & 0.60 & $24.39^{* * *}$ \\
\hline Tension/Anxiety $c, b, d$ & 1.52 & 0.50 & 1.48 & 0.42 & 0.13 \\
\hline Hyperactivity ${ }^{c}$ & 2.78 & 0.75 & 2.26 & 0.69 & $32.97^{* * *}$ \\
\hline CTRS Globaleb & 2.58 & 1.27 & 2.15 & 1.25 & $8.99 * *$ \\
\hline $\mathrm{CASQ}^{\circ}$ & 17.30 & 7.33 & 13.20 & 6.10 & $20.18^{* * *}$ \\
\hline \multicolumn{6}{|l|}{$\mathrm{ABC}$} \\
\hline Irritability $(\mathrm{S})^{f}$ & 12.38 & 10.74 & 8.39 & 7.89 & $6.22^{*}$ \\
\hline Lethargy/ Social Withdrawal $(L)^{f}$ & 5.96 & 7.65 & 4.76 & 5.50 & 0.29 \\
\hline Stereotypic Behavior $(\mathrm{L})^{f}$ & 3.40 & 4.23 & 2.39 & 3.46 & 2.42 \\
\hline Hyperactivity/Noncompliance $\mathrm{f}^{f}$ & 26.58 & 13.70 & 18.61 & 11.89 & $17.87^{* * *}$ \\
\hline Inappropriate Speech $(S)^{f}$ & 3.48 & 3.42 & 2.57 & 2.75 & 3.97 \\
\hline \multicolumn{6}{|l|}{ Parent } \\
\hline \multicolumn{6}{|l|}{ RBPC } \\
\hline Conduct Problems & 19.39 & 11.20 & 17.66 & 10.48 & $5.26^{*}$ \\
\hline Attention Problemsb & 15.03 & 7.34 & 14.19 & 6.57 & 3.45 \\
\hline Anxiety/Social Withdrawals,b & 3.98 & 3.96 & 3.95 & 3.82 & 0.01 \\
\hline Psychotic Behavior $(S) g, b$ & 2.64 & 2.78 & 2.39 & 2.52 & 2.20 \\
\hline Motor Excess (S)g & 5.19 & 2.72 & 4.47 & 2.59 & $7.04^{* *}$ \\
\hline \multicolumn{6}{|l|}{$\mathrm{ABC}$} \\
\hline Irritability & 15.28 & 10.51 & 14.36 & 10.61 & 0.59 \\
\hline Lethargy/Social Withdrawal (L)d & 2.11 & 2.65 & 1.94 & 3.16 & 3.92 \\
\hline Stereotypic Behavior (I) & 1.91 & 3.39 & 1.08 & 2.02 & 0.24 \\
\hline Hyperactivity/Noncompliance ${ }^{b}$ & 27.69 & 14.06 & 22.71 & 12.83 & $9.76^{* *}$ \\
\hline InappropriateSpeech & 4.09 & 3.38 & 4.00 & 3.37 & 0.04 \\
\hline CASQ & 15.34 & 8.13 & 15.30 & 7.93 & 0.04 \\
\hline Global rating ${ }^{\mathrm{h}}$ & 4.41 & 2.55 & 5.84 & 2.53 & $8.10^{* *}$ \\
\hline
\end{tabular}

Note. Transformations are coded as follows: $\mathrm{I}=$ inverse $+1 ; \mathrm{L}=\log ; \mathrm{S}=$ square root $+1 . \mathrm{ABC}=\mathrm{Aberrant}$ Behavior Checklist CASQ = Conners' Abbreviated Symptom Questionnaire; $\mathrm{CTRS}=$ Conners' Teacher Rating Scale; $\mathrm{RBPC}=$ Revised Behavior Problem Checklist.

adf $=1,79$.

bEffect of Study significant.

${ }^{c} d f=1,78$.

${ }^{\mathrm{d}}$ Drug $\times$ Study interaction significant.

edf $=1,69$.

f $d f=1,48$.

$8 d f=1,84$.

h $d f=1,56$ (higher scores reflect improvement).

${ }^{*} p<0.05 ;{ }^{* *} p<0.01 ;{ }^{* * *} p<0.001$.

Table 1. Effects of Methylphenidate on Clinical Variables 
Table 2. Percentage of Drug Responders as FUNCTION OF DEGREE OF CHANGEa

\begin{tabular}{lccc}
\hline $\begin{array}{l}\text { Extent of } \\
\text { change }\end{array}$ & $\begin{array}{c}\text { Number of } \\
\text { subjects }\end{array}$ & $\begin{array}{c}\% \text { of } \\
\text { subjects }\end{array}$ & $\begin{array}{c}\text { Cumulative } \\
\%\end{array}$ \\
\hline$\geq 51 \%$ Improvement & 20 & 25 & 25 \\
$41-50 \%$ Improvement & 6 & 7 & 32 \\
31-40\% Improvement & 10 & 12 & 44 \\
21-30\% Improvement & 6 & 7 & 52 \\
$1-20 \%$ Improvement & 12 & 15 & 67 \\
No change/worse & 27 & 33 & 100 \\
\hline
\end{tabular}

aChange was calculated using the following formula: (Placebo - MPH) $\div$ Placebo.

Table 2. Percentage of Drug Responders as Function of Degree Change ${ }^{\mathrm{a}}$

scores for these children. The data were analyzed as a function of (a) mental age or IQ, (b) drug, and (c) study. A significant interaction between either mental age or IQ and drug can be taken as evidence that the former variables moderated response to medication. There were three significant interactions $(p<0.01)$ for mental age on the following variables: CPT seat movement, MTS speed, and CTRS Inattention subscale. In each case, the group with higher mental ages ( $\geq 4.6$ years) showed more improvement than the group with lower mental ages ( $<4.6$ years).

Two of the findings for IQ reached the 0.01 level of significance: on CPT omission errors, $F(1,58)=9.26, p=0.004$, and CPT commission errors, $F(1,57)=8.01, p=0.006$. Lower IQ participants showed minimal decline in omission errors (mean placebo $=13.62$, mean $\mathrm{MPH}=$ 12.38 ), whereas those having higher IQs had very sizable error reductions (mean placebo $=7.92$, mean $\mathrm{MPH}=4.12$ ). The same pattern was found for $\mathrm{CPT}$ commission errors (mean placebo $=$ 22.00, mean $\mathrm{MPH}=21.33$ for lower IQ; mean placebo $=12.90$, mean $\mathrm{MPH}=4.33$ for higher IQ).

Looking at IQ and mental age in a little more detail, we split the children by IQ $(50 />50)$ and mental age ( $\leq 4.6 />4.6$ years) and compared these by chi-square tests with clinician's evaluation of clinical response, determined as each participant exited the study. IQ, but not mental age, was significantly associated with clinical response, $x^{2}(1)=9.63, p=0.003$. Of the 31 children with IQs of 50 or below, only $6(19.4 \%)$ were considered to be responders, whereas 30 of 56 $(53.6 \%)$ children with IQs above 50 were deemed responders.

Finally, we examined age and sex to see if they moderated clinical response by conducting another set of three-way ANOVA (e.g., Sex Study Drug). The number of significant interactions did not surpass chance. Hence, these variables did not seem to alter treatment outcome.

\section{Discussion}

\section{Limitations}

There were at least two limitations of the present study. The first is that different diagnostic 


\begin{tabular}{|c|c|c|c|c|c|}
\hline \multirow[b]{2}{*}{ Variable } & \multicolumn{2}{|c|}{ Placebo } & \multicolumn{2}{|c|}{ Methylphenidate } & \multirow[b]{2}{*}{$\mathrm{F}$} \\
\hline & Mean & $S D$ & Mean & $S D$ & \\
\hline \multicolumn{6}{|l|}{ MTS taska } \\
\hline Accuracy $(\%)(S)^{b}$ & 76.31 & 18.43 & 78.84 & 17.38 & $8.24^{* *}$ \\
\hline Longest delay (S) & 5.42 & 2.91 & 5.80 & 3.19 & 2.05 \\
\hline Mean delay & 2.89 & 1.55 & 3.09 & 1.71 & 1.08 \\
\hline Response time (S) & 2.17 & 0.83 & 1.96 & 0.66 & $7.76^{* *}$ \\
\hline Response speed & 0.66 & 0.18 & 0.67 & 0.19 & 0.30 \\
\hline \multicolumn{6}{|l|}{ MFF task $\mathrm{k}^{\mathrm{a}}$} \\
\hline Accuracy $(\%)^{c}$ & 54.68 & 16.29 & 57.88 & 16.37 & $4.00^{*}$ \\
\hline Response time (S) & 7.96 & 3.64 & 7.30 & 2.75 & 2.57 \\
\hline \multicolumn{6}{|l|}{$\mathrm{CPT}^{\mathrm{d}}$} \\
\hline Omission errors (S) & 9.74 & 10.56 & 5.84 & 8.32 & $1752^{* * *}$ \\
\hline Commission errors (L) & 14.72 & 15.98 & 7.52 & 11.29 & $2532^{* * *}$ \\
\hline Response timed & 1.18 & 0.29 & 1.09 & 0.30 & $9.29^{* *}$ \\
\hline \multicolumn{6}{|l|}{ Seat movement } \\
\hline MTS task net $(S)^{e}$ & 85.77 & 63.28 & 81.37 & 45.88 & 0.06 \\
\hline MFF task $(S)^{a}$ & 53.33 & 47.15 & 45.22 & 36.81 & 1.47 \\
\hline CPT net $(\mathrm{S})^{\mathrm{c}, \mathrm{d}}$ & 160.91 & 123.82 & 106.91 & 90.44 & $15.68^{* * *}$ \\
\hline \multicolumn{6}{|l|}{ Cardiovascular } \\
\hline Heart rate $\mathrm{f}^{\prime}$ & 87.99 & 16.57 & 91.93 & 12.75 & $7.40^{* *}$ \\
\hline Diastolic BPg & 68.38 & 9.19 & 71.30 & 9.23 & $5.35^{*}$ \\
\hline Systolic BPf & 103.82 & 11.87 & 105.92 & 10.42 & $3.78^{*}$ \\
\hline
\end{tabular}

Note: Transformations are coded as follows: $\mathrm{L}=\log ; \mathrm{S}=$ square root $+1 . \mathrm{BP}=$ blood pressure; $\mathrm{CPT}=\mathrm{Continuous}$

Performance Task; MFF = Matching Familiar Figures; MTS = Matching to Sample.

adf $=1,59$.

${ }^{b}$ Drug $\times$ Study interaction signifcant.

cMain effect of study significant.

$\mathrm{d} d f=1,60$.

edf $=1,44$.

f $d f=1,84$.

$8 d f=1,78$.

${ }^{*} p<0.05 ;{ }^{* *} p<0.01 ;{ }^{* *} p<0.001$.

Table 3. Effects of Methylphenidate on Cognitive, Activity, and Cardiovascular Variables versions of the DSM were used to select children for these studies, which spanned about an 11-year period. However, this is mitigated somewhat by the fact that the same parent and teacher rating scales were used for each study, and subjects needed to meet minimal criteria on these as well. Second, the dosage regimen used $(0.40 \mathrm{mg} / \mathrm{kg}$ given only in the morning) was extremely conservative and was based in part on clinical experience with this population, which can be more sensitive to medication and show more side effects than in typically developing children (discussed more below). More aggressive dosing or clinical-style titration may have yielded a higher response rate (and possibly more side effects).

\section{Clinical efficacy}

To our knowledge, this is the largest sample of children with low IQ and ADHD ever compiled. The first and most obvious conclusion is that MPH is obviously helpful for children with low IQ and clear-cut ADHD symptoms, despite the very conservative dosing (once a day) used. Significant changes were evident on a variety of teacher and parent variables, especially those related to inattention and overactivity.

Nevertheless, the rate (and perhaps degree) of clinical response appeared to be less than in typically developing children with ADHD (e.g., Barkley 1998; The MTA Cooperative Group 1999). For example, the $44 \%$ of children rated as showing a decline of more than or equal to $30 \%$ on the CASQ is clearly below the rate of $65-75 \%$ so commonly reported as responders in 
normal-ability children (Arnold 2000; Barkley 1998; Greenhill et al. 2001; The MTA Cooperative Group 1999), although the dosage difference may account for some of the difference in response. The effect sizes observed here (mean Cohen's $d$ of 0.57 for teachers and 0.39 for parents) were clearly smaller than those seen in typically developing children (usually at least 0.80 and 0.70 for teachers and parents, respectively). For instance, the MTA Cooperative Group (Greenhill et al. 2001 ), in the placebo-controlled titration of 270 children, found effect sizes of 0.9 for teacher and 0.8 for parent ratings.

Our standardized dose of $0.4 \mathrm{mg} / \mathrm{kg}$ given once daily was clearly below average doses used in typically developing children with ADHD (Arnold 2000; The MTA Cooperative Group 1999), and it may have been suboptimal for many participants. Nevertheless, parents were able to detect MPH's effects, despite the fact that the drug was given only in the morning and although only minor drug effects may have been visible after the school day. It is quite possible that MPH (as well as other drugs) may have to be given in more conservative doses in patients with developmental disabilities, as suggested elsewhere (Arnold et al. 1998). Handen and associates found high rates of side effects (e.g., dysphoria, tics, lack of social responsiveness) in such children, especially with $0.6 \mathrm{mg} / \mathrm{kg}$, the higher of two doses used (Handen et al. 1991; 2000). In one study, medication needed to be discontinued for 6 of 27 children $(22 \%)$ with developmental disabilities because of motor tics or severe social withdrawal; 2 children with social withdrawal were not exposed to the larger of two planned MPH doses $(0.3$ and $0.6 \mathrm{mg} / \mathrm{kg})$, and the higher dose needed to be discontinued for another child who developed severe irritability (Handen et al. 1991). In a study of 11 preschoolers with developmental disabilities, 5 of 10 children (50\%) experienced serious side effects (primarily irritability and social withdrawal) at the $0.6-\mathrm{mg} / \mathrm{kg}$ MPH dose $(0.3$ and $0.6 \mathrm{mg} / \mathrm{kg}$ were used) (Handen et al. 1999). The higher dose was not given to an additional child who experienced irritability, crying, and anxiety at $0.3 \mathrm{mg} / \mathrm{kg}$. Furthermore, although our doses were conservative, they were also internally consistent across all children assessed here. Thus, the more heterogeneous response in the lower IQ children cannot be considered to be merely a vagary of the dosing procedure.

Whereas IQ less than 50 was associated with a more heterogeneous response than found in higher-functioning children, we do not feel that this should preclude clinical trials in lower-functioning children. With the exception of one child with PDD-NOS who began to bite his wrist while taking MPH (Aman et al. 1991), we can recall no other child who showed severe side effects with the drug at this low dose. Hence, psychostimulants are often still worth a try in such youngsters, starting with a low dose and titrating cautiously.

\section{Effects on cognitive-motor variables}

The pattern we observed here was very much in keeping with what has been found in typically developing ADHD children, with the greatest effects observed in attentional variables (Aman 1978; Barkley et al. 1999; Douglas and Peters 1979) and in motor activity (Barkley 1998; Sprague and Sleator 1973, 1977; Werry and Aman 1975). Thus, the mechanism of change appears to be quite consistent regardless of clinical group. However, it is interesting that the significant decreases in seat activity were confined to the CPT, suggesting considerable task specificity in motor overflow.

\section{Factors associated with drug response}

As noted earlier, higher IQ and (for some variables) higher mental age were sometimes associated with a better drug response. This is consistent with one hypothesis that attentional variables may moderate clinical response for some children (Aman 1982, 1996; Aman and 
Langworthy 2000). However, other explanations may account for these associations better, and not all attempts to predict outcome by reference to IQ have observed a relation (e.g., Handen et al. 1994; Mayes et al. 1994).

\section{Conclusions}

To sum up, it is clear that MPH is effective in children with low IQ and ADHD symptoms, especially with IQ down to 50. At the same time, stimulants do not appear to work as well in such children as in children with normal IQ and ADHD. This may be reflected both in the number of responders and in the magnitude of response. In a review of the mental retardation and developmental disabilities literature (Aman 1996), an overall response rate of 54\% was found. Although this may not be as good as the frequently cited figure of $65-75 \%$ for children with normal IQ, this is still a reasonable probability of response with a drug that has relatively few side effects.

The observation that psychostimulants were less successful in patients with lower mental age and IQs of below 50 may be consistent with a lower rate of response in preschoolers with ADHD (Arnold 2002). By definition, preschoolers have lower mental ages than school-age children. Nevertheless, even in children with low IQ/low mental age, psychostimulants (because of their favorable side-effect profile) are still worth serious consideration in children with prominent ADHD. However, clinicians may wish to employ lower test doses in certain cases considered to be at high risk (e.g., those with severe self-injury, stereotypic behavior, or severe autism).

\section{Acknowledgments}

Study 1 was supported by a grant from the Medical Research Council of New Zealand; studies 2 and 3 were supported by research grants from the National Institute of Mental Health (Grant MH 44122). The authors thank Dr. Rosemary Marks (Children's Hospital of Auckland), Dr. Richard A. Kern (private practice, Columbus, Ohio), Sarah Turbott (Auckland School of Medicine), and Debbie E. McGhee and Patricia Wolford (former research coordinators).

\section{References}

Aman MG: Stimulant drug effects in developmental disorders and hyperactivity: Toward a resolution of disparate findings. J Autism Dev Disord 12:385-398, 1982

Aman MG: Stimulant drugs in the developmental disabilities revisited. J Dev Phys Disabil 8: 347-365, 1996.

Aman MG: Drugs, learning and the psychotherapies. In: Pediatric Psychopharmacology The Use of Behavior Modifying Drugs in Children. Edited by Werry JS. New York, Brunner/Mazel, pp 79-108, 1978.

Aman MG: Applications of computerized cognitive-motor measures to the assessment of psychoactive drugs. In: Assessing Cognitive Function in Epilepsy. Edited by Dodson WE, Kinsbourne M, Hiltbrunner B. New York, Demos Publications, 1991, pp 69-96.

Aman MG, Kern RA, McGhee DE, Arnold LE: Fenfluramine and methylphenidate in children with mental retardation and ADHD: Clinical and side effects. J Am Acad Child Adolesc Psychiatry 32:851-859, 1993.

Aman MG, Kern RA, Osborne P, Tumuluru R, Rojahn J, Del Medico V: Fenfluramine and methylphenidate in children with mental retardation and borderline IQ: Clinical effects. Am J Ment Retard 101:521-534, 1997.

Aman MG, Langworthy K: Pharmacotherapy for hyperactivity in children with autism and PDD-NOS. J Autism Dev Disord 30:451-459, 2000.

Aman MG, Marks RE, Turbott SH, Wilsher CP, Merry SN: Clinical effects of MPH and thioridazine in intellectually subaverage children. J Am Acad Child Adolesc Psychiatry 30:246-256, 1991.

Aman MG, Pearson DA: Monitoring and measuring drug effects. II. Behavioral, emotional, and cognitive effects. In: Practitioner's Guide to Psychoactive Drugs for Children and Adolescents, 2nd ed. Edited by Werry JS, Aman MG. New York, Plenum, 1999, pp 99-164.

Aman MG, Singh NN, Stewart AW, Field CJ: The Aberrant Behavior Checklist: A behavior rating scale for the assessment of treatment effects. Am J Ment Defic 89:485-491, 1985. 
American Psychiatric Association: Diagnostic and Statistical Manual of Mental Disorders, 3rd ed. (DSM-III). Washington (DC), American Psychiatric Association, 1980.

American Psychiatric Association: Diagnostic and Statistical Manual of Mental Disorders, 3rd ed., rev. (DSM-III-R). Washington (DC), American Psychiatric Association, 1987.

Arnold LE: Methylphenidate versus amphetamine: A comparative review. J Atten Disord 3:200-211, 2000.

Arnold LE: Contemporary Diagnosis and Management of Attention-Deficit Hyperactivity Disorder, 2nd ed. Newtown (Pennsylvania), Handbooks in Health Care, 2002.

Arnold LE, Gadow K, Pearson DA, Varley CK: Stimulants. In: Psychotropic Medications and Developmental Disabilities: The International Consensus Handbook. Edited by Reiss S, Aman MG. Columbus (Ohio), The Ohio State University Nisonger Center, 1998, pp 229-257.

Barkley RA: Attention Deficit Hyperactivity Disorder: A Handbook for Diagnosis and Treatment, 2nd ed. New York, Guilford Press, 1998.

Barkley RA, DuPaul GJ, Conner DF: Stimulants. In: Practitioner's Guide to Psychoactive Drugs for Children and Adolescents, 2nd ed. Edited by Werry JS, Aman MG. New York, Plenum, 1999, pp 213-247.

Benson BA, Aman MG: Disruptive behavior disorders in children with mental retardation. In: Handbook of Disruptive Behavior Disorders. Edited by Quay HC, Hogan AE. New York, Kluwer, 1999, pp 559-578.

Conners CK: A teacher rating scale for use in drug studies with children. Am J Psychiatry 126:152-156, 1969.

Cumming WW, Berryman R: The complex discriminated operant: Studies of matching-to-sample and related problems. In: Stimulus Generalization. Edited by Mostofsky DI. Stanford (California), Stanford University Press, 1965, pp 284-330.

Douglas VI, Peters KG: Toward a clearer definition of the attentional deficit of hyperactive children. In: Attention and Cognitive Development. Edited by Hale GA, Lewis M. New York, Plenum, 1979, pp 173-247.

Edelbrock C: Childhood Attention Problems (CAP) Scale. Available from Dr. C. Edelbrock, Pennsylvania State University, University Park, PA, 1978.

Gadow KD: Prevalence and efficacy of stimulant drug use with mentally retarded children and youth. Psychopharmacol Bull 21:291-303, 1985.

Goyette CH, Conners CK, Ulrich RF: Normative data on revised Conners Parent and Teacher Rating Scales. J Abnorm Child Psychol 6:221-236, 1978.

Greenhill LL, Swanson JM, Vitiello B, Davies M, Clevenger W, Wu M, Severe JB, Arnold LE, Abikoff HB, Conners CK, Elliott G, Hechtman L, Hinshaw SP, Hoza B, Jensen PS, Kraemer HC, March JS, Newcorn JH, Pelham WE, Wells K, Wigal T: Impairment and deportment responses to different methylphenidate doses in children with ADHD: The MTA titration. J Am Acad Child Adolesc Psychiatry 40:180-187, 2001.

Hagerman RJ, Murphy MA, Wittenberger MD. A controlled trial of stimulant medication in children with the fragile X syndrome. Am J Med Genet 30:377-392, 1988.

Handen BL, Breaux AM, Gosling A, Ploof DL, Feldman H. Efficacy of methylphenidate among mentally retarded children with attention deficit hyperactivity disorder. Pediatrics 86:922-930, 1990.

Handen BL, Breaux AM, Janosky J, McAuliffe S, Feldman H, Gosling S: Effects and non-effects of methylphenidate in children with mental retardation and ADHD. J Am Acad Child Adolesc Psychiatry 31:455-461, 1992.

Handen BL, Feldman H, Gosling A, Breaux AM, McAuliffe S: Adverse side effects of methylphenidate among mentally retarded children with ADHD. J Am Acad Child Adolesc Psychiatry 30:241-245, 1991.

Handen BL, Feldman H, Lurier M, Husar PJ: Efficacy of methylphenidate among preschoolers with developmental disabilities and ADHD. J Am Acad Child Adolesc Psychiatry 38:805-872, 1999.

Handen BL, Janosky J, McAuliffe S, Breaux AM, Feldman H: Prediction of response to methylphenidate among children with ADHD and mental retardation. J Am Acad Child Adolesc Psychiatry 33:1185-1193, 1994.

Handen BL, Johnson CR, Lubetsky M: Efficacy of methylphenidate among children with autism and symptoms of ADHD. J Autism Dev Disord 35:245-255, 2000.

Handen BL, McAuliffe S, Caro-Martinez L: Learning effects of methylphenidate in children with mental retardation. J Dev Phys Disabil 8: 335-346, 1996.

Kagan J: Reflection-impulsivity and reading ability in primary grade children. Child Dev 36:609-628, 1965.

Mayes SD, Crites DL, Bixler EO, Humphrey FJ 2nd, Mattison, RE: Methylphenidate and ADHD: Influence of age, IQ, and neurodevelopmental status. Dev Med Child Neurol 36:1099-1107, 1994.

The MTA Cooperative Group: A 14-month randomized clinical trial of treatment strategies for attention-deficit/hyperactivity disorder. Arch Gen Psychiatry 56:1073-1086, 1999.

Pearson DA, Santos CW, Roache JD, Casat CD, Loveland KA, Lachar D, Lane DM, Faria LP, Cleveland LA: 
Treatment effects of methylphenidate on behavioral adjustment in children with mental retardation and ADHD. J Am Acad Child Adolesc Psychiatry 42:209-216, 2003.

Quay HC, Peterson DR: Manual for the Revised Behavior Problem Checklist. Odessa (Florida), Psychological Assessment Resources, 1987.

Richters J, Arnold LE, Jensen PS, Abikoff H, Conners CK, Greenhill LL, Hechtman L, Hinshaw SP, Pelham WE, Swanson JM: NIMH collaborative multisite multimodal treatment study of children with ADHD: I. Background and rationale. J Am Acad Child Adolesc Psychiatry 34:987-1000, 1995.

Sprague RL, Sleator EK: Effects of psychopharmacologic agents on learning disorders. Pediatr Clin North Am 20:719-735, 1973.

Sprague RL, Sleator EK: Methylphenidate in hyperkinetic children: Differences in dose effects on learning and social behavior. Science 198: 1274-1276, 1977.

Ullmann RK, Sleator EK, Sprague RL: ACTeRS Teacher and Parent Forms Manual, 2nd ed, Champaign, IL, MetriTech Inc, 1997.

Werry JS, Aman MG: Methylphenidate and haloperidol in children. Effects on attention, memory, and activity. Arch Gen Psychiatry 32:790-795, 1975.

Wilens TE, Spencer TJ: The stimulants revisited. Child Adolesc Psychiat Clin North America 9:573-603, 2000. 